\title{
PLANEJAMENTO E GESTÃO DO TURISMO
}


Sales, A.A.M. Descentralização e regionalização na política de circuitos turísticos em Minas Gerais. Anais do XII Encontro Nacional de Turismo com Base Local. Revista Brasileira de Ecoturismo, São Paulo, v.5, n.4, nov-2012, p.781.

\title{
Descentralização e regionalização na política de circuitos turísticos em Minas Gerais
}

\author{
Álvaro Américo Moreira Sales* \\ *Fundação Municipal de Cultura de Belo Horizonte \\ E-mail: alvaromsales@gmail.com
}

A gestão pública do turismo no Brasil e em Minas Gerais adota a descentralização em seus programas como meio para abranger um vasto território e os municípios. $\mathrm{Na}$ maioria desses programas descentralizadores, há o caráter de regionalização. Esta incentiva não só a descentralização das tomadas de decisões entre os poderes centrais e locais, mas também aumenta a influência das associações, agências e organizações locais na formatação das políticas públicas do turismo. Este trabalho se propõe a investigar e analisar a política de Circuitos Turísticos de Minas Gerais nos aspectos de descentralização e regionalização. Tais aspectos estão presentes na política empreendida no estado, mas busca-se compreender em que medida a descentralização e a regionalização de fato ocorrem e quais são os resultados. Para tal, empreendeu-se uma pesquisa em trabalhos que já abordaram o tema, análise de dados e entrevista junto à Secretaria de Estado de Turismo. Comprovou-se o caráter descentralizador e regionalizante na política, que proporciona o empoderamento e a organização dos entes inferiores.

PALAVRAS-CHAVE: Descentralização; Regionalização. Política Pública; Turismo. 
Santos, A.A.; Silva, E.A.; Santiago, T.M.O.; Ambrósio, R.V.; Fonseca, R.A. O Ecoturismo como fonte de lazer e entretenimento: do empreendimento constituído ao desenvolvimento local. Anais do XII Encontro Nacional de Turismo com Base Local. Revista Brasileira de Ecoturismo, São Paulo, v.5, n.4, nov-2012, p.782.

\title{
O Ecoturismo como fonte de lazer e entretenimento: do empreendimento constituído ao desenvolvimento local
}

\author{
Anderson Alves Santos*, Edson Arlindo Silva*, Thais Muniz Ottoni Santiago*, \\ Rafaela Vidal Ambrósio*, Reinaldo Aparecida Fonseca ${ }^{\star \star \star}$ \\ *Universidade Federal de Lavras, ** Universidade Federal de Viçosa, \\ ***Universidade Federal de São João Del Rei \\ E-mails: alvessanto@gmail.com, edsonsilva@ufv.br, thaismottoni@gmail.com, \\ rafavidalambrosio@yahoo.com.br, fonseca.1959@hotmail.com
}

O empreendimento constituído voltado à promoção de lazer e entretenimento insere estas iniciativas em um conjunto de estratégias empresarias que tem por finalidade a geração de trabalho e renda aos prestadores de serviços nesta área. O Balneário Paradise, objeto de estudo do presente trabalho, carece de um desafiador instrumento de divulgação que mostre as belezas naturais do lugar, as condições para receber os usuários e para a ampliação da infraestrutura local. Dessa forma, o estudo revelou a necessidade de desenvolver um conjunto de estratégias empresariais voltadas para implantar o ecoturismo no Balneário Paradise: i) Ampliar o parque aquático, para proporcionar aos usuários satisfação ao frequentarem o balneário, ii) Desenvolver um plano de ação estratégico para áreas de lazer diversificadas, sem onerar o orçamento previsto, iii) Traçar metas para desenvolver o ecoturismo, aproveitando as potencialidades naturais do lugar e iv) Estudar o comportamento dos usuários com o intuito de satisfazer suas expectativas em relação aos serviços oferecidos, através de um trabaIho de campo. Nesse contexto, foi preciso desenvolver planos e ações para que a divulgação tenha a eficácia pretendida e consiga atingir o público-alvo.

PALAVRAS-CHAVE: Ecoturismo; Entretenimento; Marketing. 


\title{
Planejamento turístico: estudo de caso da cidade de Belém (PA)
}

\author{
Celisse Maria Brito*, Heliani Socorro Sá** \\ *Instituto de Estudos Superiores da Amazônia, **Universidade Federal do Pará \\ E-mail: celissinha@hotmail.com
}

O turismo é uma das atividades que mais cresce no mundo, tornando-se promissora para muitos países. Nesse contexto, as regiões que mais se destacam na atividade são as que dispõem de atrativos naturais e culturais juntamente com uma infraestrutura adequada, estimulando assim o deslocamento de grandes fluxos de turistas e visitantes para a determinada localidade, além de fomentar o crescimento do setor turístico, gerando benefícios socioeconômicos para os envolvidos na atividade. Por isso é extremante necessário que as cidades estejam preparadas para receber os turistas atendendo ou até mesmos superando as expectativas dos mesmos. Nessa perspectiva, o presente artigo pretende esclarecer de que forma o planejamento Turístico vem sendo aplicado no âmbito logístico e estrutural da cidade de Belém no sentido de atender as demandas turísticas e satisfazendo as pessoas que usufruem dos atrativos turísticos. Visto que esse tipo de planejamento é a base de toda ação voltada para a atividade turística, que analisa um determinado espaço geográfico, diagnosticando seu desenvolvimento e fixando um modelo de atuação, mediante o estabelecimento de metas e objetivos proporcionando ações eficazes, com a interação de todos os agentes do Turismo, o órgão público, privado e a comunidade. Com isso o artigo explanará quais os entraves encontrados e as dificuldades na gestão, pois sabe-se que o planejamento turístico adequado deve vislumbrar melhorias em infraestrutura que atendam não somente o turista mas principalmente a população local.

PALAVRAS-CHAVE: Turismo; Planejamento; Planejamento Turístico; Infraestrutura. 
Maranhão, C.H.S.; Azevedo, F.F. Contribuições do Turismo de Base Local para o processo de pla nejamento e gestão do turismo em Natal (RN). Anais do XII Encontro Nacional de Turismo com Ba= se Local. Revista Brasileira de Ecoturismo, São Paulo, v.5, n.4, nov-2012, p.784.

\title{
Contribuições do Turismo de Base Local para o processo de planejamento e gestão do turismo em Natal (RN)
}

\author{
Christiano Henrique da Silva Maranhão*, Francisco Fransualdo Azevedo* \\ *Universidade Federal do Rio Grande do Norte \\ E-mail: ffazevedo@gmail.com
}

Motivado pela necessidade de se planejar e gerir o turismo no município de Natal, inserindo, igualitariamente, oportunidades que visam à participação de todos os agentes nos processos decisórios é que este artigo tem como objetivo analisar de que forma o turismo de base local pode contribuir para (re) direcionar o processo de planejamento e gestão do turismo em Natal/RN, norteando-o para uma maior inserção da comunidade local na tomada de decisão vinculada ao planejamento e a gestão do turismo natalense. Do ponto de vista metodológico, este estudo se caracteriza por uma natureza qualitativa, com tipologia descritivo-exploratória. A análise construída neste artigo aponta que 0 atual modelo de expansão do turismo vigente em Natal é hegemônico e contraditório, apresentando relações verticais de gestão e planejamento. Em contraposição, o desenvolvimento endógeno, que visa à inserção das populações no processo de decisão e na cadeia produtiva do turismo, apresenta-se como alternativa mais justa, menos excludente, mais democrática e minimizadora das contradições geradas pelo sistema capitalista no modo de planejar e gerir a atividade turística em comunidades locais.

PALAVRAS-CHAVE: Planejamento; Gestão; Turismo; Comunidade Local. 


\title{
Turismo Religioso em Santo Expedito (SP)
}

\author{
Claudemira Azevedo Ito* \\ *Universidade Estadual Paulista Julio de Mesquita Filho \\ E-mail: ito@fct.unesp.br
}

Este trabalho trata do turismo religioso que ocorre na cidade de Santo Expedito, que possui cerca de 3 mil habitantes, localizada no interior do Estado de São Paulo, na região de Presidente Prudente. A origem da cidade sempre esteve associada à devoção ao Santo Expedito. Hoje o turismo é a atividade que mais cresce no município, pois em algumas festividades recebe até 50.000 visitantes. Neste trabalho discutimos os conceitos de turismo religioso e sua diferenciação de peregrino ou romeiro. Em Santo Expedito encontramos o peregrino, pessoa que mergulha no sagrado participando dos eventos religiosos, e também há o turista, que está mais interessado nos shows, na socialização e diversão, deixando em segundo plano as questões religiosas. A principal conclusão que se extraiu foi à capacidade que o capitalismo tem de se articular com todas as esferas da vida, nesse caso com a fé e a religião, tornando o que seriam momentos de orações em momentos de recreação e consumo, associados à fé.

PALAVRAS-CHAVE: Turismo Religioso; Santo Expedito; Peregrino. 


\section{Perspectivas e ações de diferentes atores sociais na gestão e sustentabilidade do turismo em Vargem (SP)}

\section{Cristiane Ferraz e Silva Suarez*, Nayra de Moraes Gonçalves**, João Luiz de Moraes Hoeffel ${ }^{\star \star *}$}

*Universidade São Francisco, **Moinho d'Água Treinamentos, ${ }^{* * *}$ Faculdades Atibaia

E-mails: cristiane.suarez@saofrancisco.edu.br, nayragoncalves@gmail.com, jlhoeffel@gmail.com

Este trabalho originou-se da constatação de que a área de estudo, o município de Vargem (SP), vem apresentando diversos problemas, principalmente relacionados ao desenvolvimento do turismo de forma desordenada, decorrentes de variadas alterações socioambientais regionais. O fato de o município estar inserido em uma Unidade de Conservação, a Área de Proteção Ambiental do Sistema Cantareira, enfatiza a necessidade de estudos que contribuam para a elaboração de políticas públicas que possam embasar planos turísticos sustentáveis aliados à conservação dos recursos naturais. Desta forma, este trabalho teve como objetivo identificar perspectivas e ações de diferentes atores sociais na gestão e sustentabilidade do turismo no município. Visando contemplar os objetivos propostos foram adotados procedimentos metodológicos que envolveram levantamentos bibliográficos, trabalhos de campo nos quais foram realizadas entrevistas e aplicação questionários semiestruturados, bem como a posterior análise dos dados. Os resultados obtidos possibilitaram apresentar uma discussão sobre turismo na visão dos diferentes atores sociais entrevistados e as estratégias e ações existentes para o turismo sustentável e a conservação ambiental em Vargem.

PALAVRAS-CHAVE: Gestão; Sustentabilidade; Turismo; Atores Sociais. 
Cardoso, D.S. Agenciamentos culturais para a implantação do Turismo de Base Comunitária: uma análise dos desafios de turistificação comunitária a partir do Bairro de Santa Cruz (RJ) e adjacências. Anais do XII Encontro Nacional de Turismo com Base Local. Revista Brasileira de Ecoturismo, São Paulo, v.5, n.4, nov-2012, p.787.

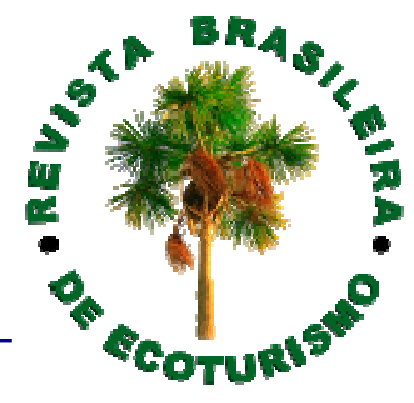

\title{
Agenciamentos culturais para a implantação do Turismo de Base Comunitária: uma análise dos desafios de turistificação comunitária a partir do Bairro de Santa Cruz (RJ) e adjacências
}

\author{
Diogo da Silva Cardoso* \\ *Universidade Federal do Rio de Janeiro \\ E-mail: diogo_georeg@yahoo.com.br
}

O texto objetiva destacar os projetos e iniciativas políticas, culturais e econômicas que vem brotando nos últimos dez-vinte anos na região histórica e cultural de Santa Cruz (RJ), cujo aspecto dela indica que alternativas pós-desenvolvimentistas vêm sendo pensadas e praticadas pelos atores locais, tendo em vista um desenvolvimento comunitário mais justo e empoderador. Essa região foi, desde meados do século passado, negligenciada pelo Poder público e a iniciativa privada, e o resultado e um quadro de periferização e precarização da população local e do seu patrimônio cultural. Entretanto, Santa Cruz foi recentemente incluída no processo de especulação imobiliária tendo em vista os megaeventos esportivos e culturais que aconteceram nos próximos anos (Jornada da Juventude 2013, Olimpíadas, Copa do Mundo), e também vislumbram a possibilidade de aumentar a sua fatia na distribuição de equipamentos e receitas advindas desses investimentos de grosso calibre. Diante deste denso cenário geográfico de disputas econômicas e simbólicas, atores locais das regiões de Santa Cruz e Guaratiba (Zona Oeste) têm lançado outras ações como contraponto ao projeto conservador de transformação da cidade do Rio de Janeiro num palco de puro espetáculo e entretenimento, especulação imobiliária e geração de novos territórios exclusivistas, que obstrui a concepção original da cidade como espaço de exercício da política (polis) e de garantia da vida pública plena. Veremos em que medida os projetos e iniciativas pautados na economia solidária e comércio justo, no fortalecimento da identidade cultural territorial e na conservação do patrimônio históricocultural e ambiental urbano, oferecem soluções pós-desenvolvimentistas para a construção do cotidiano dos bairros, que trazem um contraponto às soluções dadas pelos gestores públicos, técnicos e o empresariado dominante. E o turismo de base comunitária pode ser o sistema que fará com que este ciclo de tradições e inovações aumente o seu estado de potencialidade e prossiga na construção de pontes entre a periferia da Zona Oeste e a cidade do Rio de Janeiro, garantido o desenvolvimento cultural, a geração de emprego e renda, e a inserção da região em outros contextos e circuitos.

PALAVRAS-CHAVE: Santa Cruz; Turismo de Base Comunitária; Ecomuseu; Economia Solidária; Pós-desenvolvimento. 
Pinto, F.A.; Nunes, J.O.C. As denominações de café cultura como prerrogativa de desenvolvimento da identidade organizacional do negócio: um estudo nas denominações de cafés cultura de Paris (França) e no Café Havana em Canoa Quebrada (CE). Anais do XII Encontro Nacional de Turismo com Base Local. Revista Brasileira de Ecoturismo, São Paulo, v.5, n.4, nov-2012, p.788.

\title{
As denominações de café cultura como prerrogativa de desenvolvimento da identidade organizacional do negócio: um estudo nas denominações de cafés cultura de Paris (França) e no Café Havana em Canoa Quebrada (CE)
}

\author{
Francisco Almir Pinto*, José Orlando Costa Nunes** \\ *Faculdade do Vale do Jaguaribe, ${ }^{* \star *}$ Universidade do Estado do Rio Grande do Norte \\ E-mails: almirred@hotmail.com, joseorlando@uern.br
}

Este estudo analisa com profundidade histórica e técnica a denominação da nomenclatura das casas de café cultura que atualmente se apresentam com ambientes diversificados de trabalho, onde a nomenclatura enfatizada prioriza a escolha do cliente pela visita. Para a compreensão da forma sistemática da denominação dos nomes de fantasia neste tipo de negócio é que esta pesquisa foi estruturada, objetivando compreender este tipo de formação com fins de estabelecer um quadro informativo contendo categorias apresentadas com percentuais de frequência em termos de uso das denominações de nomes de cafés cultura em Paris na França, berço de nascimento deste tipo de empresa. Para completar esse entendimento, posteriormente analisouse também um café cultura na praia de turismo internacional de Canoa Quebrada/CE. O levantamento de dados foi realizado através de livros acadêmicos e de periódicos científicos da área e da pesquisa na internet na $1^{\mathrm{a}}$ fase e para a $2^{\mathrm{a}}$ fase foi realizada uma pesquisa in loco num café cultura em pleno funcionamento na localidade acima citada. Os resultados puderam estabelecer que existam uma predominância nas particularidades da formação de nomes de cafés culturas com prioridades para especificidades de diversos tipos de nomes apresentados neste trabalho, sendo as categorias de cafés com nomes sugestivos (25\%), nomes sem nexo nas traduções (19\%) as mais citadas. Outra conclusão relevante é a compreensão que a denominação de café possui uma influência significativa na identidade do negócio, causando então um maior sucesso, conforme foi verificado no estabelecimento estudado.

PALAVRAS-CHAVES: Turismo de Praia; Identidade Organizacional; Denominações de Negócios. 


\title{
Acessibilidade no ecoturismo e turismo de aventura: atuação do poder público e privado
}

\author{
Grislayne Guedes Lopes da Silva*, Reinaldo Miranda de Sá Teles* \\ *Universidade de São Paulo \\ E-mails: gris-guedes@uol.com.br, reiteles@usp.br
}

O estudo tem como principal objetivo averiguar como as empresas percebem a atuação do poder público e privado em ações direcionadas para a acessibilidade. O objeto de estudo é a acessibilidade nos segmentos de ecoturismo e turismo de aventura. Partiu-se da aplicação de pesquisa qualitativa junto às empresas destes segmentos para compreender como questões relacionadas à acessibilidade são percebidas pelos empreendedores; se o mercado está se adequando para receber esse perfil de público com deficiência ou mobilidade reduzida; e se há demonstração de preocupação e interesse em tornar atividades acessíveis para essa demanda crescente. Os principais resultados do estudo demonstram que a maioria das empresas não estão preparadas para atender esse público, porém dizem-se interessadas e dispostas em tornar seus produtos acessíveis, principalmente, se receberem apoio do poder público no que diz respeito a incentivos fiscais e na melhoria da infraestrutura básica e turística dos municípios.

PALAVRAS-CHAVES: Poder Público; Poder Privado; Acessibilidade; Pesquisa Qualitativa. 
Malta, G.A.P. Turismo e desenvolvimento: análise de uma complexa relação para contribuir com os processos comunitários. Anais do XII Encontro Nacional de Turismo com Base Local. Revista Brasileira de Ecoturismo, São Paulo, v.5, n.4, nov-2012, p.790.

\title{
Turismo e desenvolvimento: análise de uma complexa relação para contribuir com os processos comunitários
}

\author{
Guilherme Augusto Pereira Malta* \\ *Universidade Federal de Minas Gerais \\ E-mail: guilherme.malta@gmail.com
}

O turismo, do ponto de vista do desenvolvimento, é frequentemente apontado enquanto meio capaz de induzi-lo em uma dada realidade e/ou como parte de uma estratégia para se alcançá-lo. A relação entre desenvolvimento e turismo, amplamente abordada nos estudos que trabalham a noção de turismo local e comunitário, é tema principal deste trabalho, levando-se em conta a sua complexidade e amplitude. Como esforço inicial de compreensão, foram identificadas o que aqui se denominou de abordagens de desenvolvimento, ou seja, principais formas de se enxergar o turismo dentro dos processos de desenvolvimento. De maneira complementar à discussão central deste artigo será trabalhada, também, a relação existente entre os enfoques de desenvolvimento identificados e as principais perspectivas de planejamento turístico. Espera-se, dessa maneira, contribuir para a discussão em torno do turismo localcomunitário e das questões que o tema busca suscitar.

PALAVRAS-CHAVE: Desenvolvimento; Planejamento; Turismo Local Comunitário. 
Cordeiro, I.; Korossy, N.; Selva, V.S.F. Capacidade de Carga Turística da Praia dos Carneiros, Tamandaré (PE) . Anais do XII Encontro Nacional de Turismo com Base Local. Revista Brasileira de Ecoturismo, São Paulo, v.5, n.4, nov-2012, p.791.

\title{
Capacidade de Carga Turística da Praia dos Carneiros, Tamandaré (PE)
}

\author{
Itamar Cordeiro*, Nathália Korossy*, Vanice Santiago Fragoso Selva* \\ *Universidade Federal de Pernambuco \\ E-mails: itamar_cordeiro@yahoo.com.br, nathaliakorossy@gmail.com, \\ vanice.selva@gmail.com
}

Os estudos de determinação da capacidade de carga podem ser utilizados como ferramentas úteis para o planejamento de destinos turísticos sustentáveis. No entanto, muitos destinos turísticos não utilizam tal ferramenta em seus processos de planejamento. Tamandaré, município localizado no litoral sul de Pernambuco, não é exceção. Considerando que o estabelecimento de um limite máximo de usuários é um elemento que pode auxiliar no ordenamento do turismo, o presente estudo aplicou o método desenvolvido por Cifuentes et al (1992) para estimar a capacidade de carga de uma das principais praias de Tamandaré: a praia dos Carneiros. Para tanto, foram definidas duas zonas: i) zona de faixa de praia e, ii) zona de piscinas naturais. Os resultados encontrados sugerem um limite máximo de usuários de 129 visitantes/dia para a faixa de praia e de 1.161 visitantes/dia para a zona de piscinas naturais. Quando se comparam os limites sugeridos com as taxas atuais de visitantes, verifica-se que a capacidade de carga está dentro do aceitável para a zona de piscinas naturais e, acima do recomendado na zona de faixa de praia.

PALAVRAS-CHAVE: Turismo; Capacidade de Carga; Método Cifuentes; Praia dos Carneiros; Tamandaré. 
Cordovil, J.C.; Pereira, B.S.; Costa, W.L.; Nunes, P.B. Políticas públicas, atividade turística e estratégias de desenvolvimento: uma abordagem sobre o turismo em Altamira (PA). Anais do XII Encontro Nacional de Turismo com Base Local. Revista Brasileira de Ecoturismo, São Paulo, v.5, n.4, nov-2012, p.792.

\title{
Políticas públicas, atividade turística e estratégias de desenvolvimento: uma abordagem sobre o turismo em Altamira (PA)
}

\author{
José Carlos Cordovil*, Bruna Suelen Pereira**, Wagner Lima Costa*, \\ Patrícia Barbosa Nunes* \\ *Universidade Federal do Pará, **Prefeitura Municipal de Altamira \\ E-mails: jccordovil@ig.com.br, bruna.tur@hotmail.com,wa.wesley.geo@gmail.com, \\ patricia_bn@hotmail.com
}

O turismo se apresenta, no contexto atual, como importante fator de atração de divisas para os países, estados e municípios, sendo considerado uma das mais pujantes atividades econômicas. Como pratica social provoca, pelas relações que são engendradas, repercussões no espaço, promovendo a produção de diversas formas espaciais. Além disso, representa novas estratégias governamentais para o desenvolvimento. Nestes termos, o presente artigo aborda a crescente importância do turismo, como estratégia de gestão para o desenvolvimento a partir das ações deliberadas no âmbito do poder público, que resultam no incremento da atividade, tendo como foco de análise as políticas públicas de desenvolvimento das atividades turísticas pensadas e implementadas em Altamira. Assim, o trabalho procura evidenciar as políticas planejadas, por meio de um conjunto de documentos oficiais visando ao fomento da atividade turística. Em relação ao procedimento metodológico foi realizada, além do levantamento e análise documental, a pesquisa e análise bibliográfica da produção que trata das políticas de turismo pensadas para a Amazônia, Estado do Pará e por conseguinte para Altamira. Feita a organização e sistematização dos dados e informações coletadas evidencia-se as políticas de desenvolvimento do turismo em Altamira e sua relação especial com o discurso do desenvolvimento sustentável de onde emerge as políticas de incentivo ao ecoturismo.

PALAVRAS-CHAVE: Políticas de Turismo; Desenvolvimento; Ecoturismo; Amazônia; Altamira. 


\title{
Proposta de ordenamento das áreas de camping da comunidade da Prainha Branca, Guarujá (SP)
}

\author{
Marcos Buhrer Campolim*, Ana Paula Garcia*, Tathiany Regina Lima Mottola* \\ *Fundação Florestal - Secretaria de Estado do Meio Ambiente \\ E-mails: marcoscampolim@yahoo.com.br, anagarcia.bio@gmail.com, \\ tathianyl@yahoo.com.br
}

\begin{abstract}
A área de estudo localiza-se na Prainha Branca, município do Guarujá, na Serra do Guararu, local tombado pelo CONDEPHAAT (Resolução SC № 048/1992 - 112/1992) devido aos seus atributos naturais e culturais e está inserida na Área de Manejo Especial da Área de Proteção Ambiental Marinha Litoral Centro, Unidade de Conservação do Estado de São Paulo (Decreto n 53.526 - 08/10/2008). Em 2011, iniciaram-se trabalhos conjuntos entre Fundação Florestal e Sociedade Amigos da Prainha Branca, entre outras atividades, visando à regularização das atividades de camping por ser demanda emergencial da comunidade para garantir a renda dos moradores que necessitam desta atividade para subsistência. As atuais áreas de camping apresentam excesso de barracas sem estrutura sanitária adequada para atender o contingente nas áreas de camping. Este trabalho teve como objetivo a formatação de proposta de ordenamento das áreas de campings. Foram coletadas informações junto aos donos das áreas de camping de forma participativa. Os parâmetros considerados foram estrutura sanitária, área disponível e número de pessoas por barraca. Foram analisadas 27 áreas de camping. Priorizou-se a viabilização de áreas de camping para famílias tradicionais residentes. Esta proposta de ordenamento promove redução de $53,3 \%$ da quantidade de barracas, de forma ponderada entre todas as áreas atuais. Espera-se redução dos problemas ambientais da comunidade e melhoria na qualidade dos serviços prestados com melhor rendimento financeiro.
\end{abstract}

PALAVRAS-CHAVE: Comunidade Tradicional; Prainha Branca; Ordenamento de Camping; Unidade de Conservação. 
Lima, R.N. "EDIL", uma ferramenta de gestão para preservação de atrativos turísticos: uma proposta para a Lagoa da Ana Jansen (MA). Anais do XII Encontro Nacional de Turismo com Base Local: Revista Brasileira de Ecoturismo, São Paulo, v.5, n.4, nov-2012, p.794.

\title{
"EDIL”, uma ferramenta de gestão para preservação de atrativos turísticos: uma proposta para a Lagoa da Ana Jansen (MA)
}

\author{
Rozuila Neves Lima* \\ *Universidade Federal do Maranhão \\ E-mail: rozuila@hotmail.com
}

Este trabalho é produto dos estudos realizados pelo Grupo de Estudo e Pesquisa "Gestão, Marketing e Sustentabilidade do Turismo", com a linha de pesquisa - Desenvolvimento Regional e Marketing Territorial. Neste artigo apresentamos o método EDIL, uma ferramenta de gestão para preservação de atrativos turísticos. O objeto de estudo é a Lagoa da Ana Jansen, em São Luís (MA). A metodologia utilizada foi de caráter primário, com pesquisa de campo, aplicação de questionário, entrevista, e fontes secundária, com levantamento bibliográfico e fotográfico. Através dessa metodologia foi possível identificar as necessidades, limitações de ordem estrutural e de gestão, ocasionando a fragilidade do espaço comprometendo sua função de proporcionar entretenimento e lazer para a comunidade local. Diante desses resultados negativos propomos a aplicação do EDIL, uma ferramenta de gestão para preservar esse atrativo turístico, a Lagoa da Ana Jansen.

PALAVRAS-CHAVE: Turismo; Gestão; Atrativo Turístico. 
Lopes-Junior, W.M. Estudo da modalidade de turismo e da infraestrutura instalada no litoral dos municípios de Campos dos Goytacazes, São João da Barra e São Francisco de Itabapoana, situados na região norte fluminense como subsídio ao planejamento turístico. Anais do XII Encontro Nacional de Turismo com Base Local. Revista Brasileira de Ecoturismo, São Paulo, v.5, n.4, nov-2012, p.795.

\title{
Estudo da modalidade de turismo e da infraestrutura instalada no litoral dos municípios de Campos dos Goytacazes, São João da Barra e São Francisco de Itabapoana, situados na região norte fluminense como subsídio ao planejamento turístico
}

\author{
Wilson Martins Lopes Junior* \\ *Universidade Federal Fluminense \\ E-mail: prof.wilsonmartinslopes@uol.com.br
}

As diferentes transformações provocadas no espaço geográfico pelo turismo configuram-se em tema de estudo da geografia do turismo, uma vez que a ciência geografia estuda a organização espacial. O diagnóstico e o entendimento da modalidade de turismo exercido numa localidade, assim como a identificação da infraestrutura turística existente favorece na compreensão das transformações socioespaciais ocorridas nos municípios turísticos. Desta forma colabora-se com o planejamento e gestão do turismo que compreende a implementação de política de desenvolvimento do turismo e do plano de administração deste setor econômico. Nesta perspectiva essa pesquisa analisa a modalidade de turismo predominante no litoral dos municípios de Campos dos Goytacazes, São João da Barra e São Francisco de Itabapoana, no norte fluminense, identificando suas infraestruturas, o que colabora com a gestão pública em seu planejamento. Enquanto método se destacam levantamentos de campo associados a técnicas de observação, aplicação de questionários e entrevistas para levantamento da infraestrutura turística e entendimento da modalidade de turismo dos municípios pesquisados. Preliminarmente identificou-se que o turismo de segunda residência é expressivo nestes municípios. Também, notou-se falta de infraestrutura alimentícia, de hospedagem, serviços turísticos e sinalização turística.

PALAVRAS-CHAVE: Geografia do Turismo; Turismo Litorâneo; Turismo Norte Fluminense. 
Lopes-Junior, W.M.L. Geografia urbana e as novas centralidades como subsídio as pesquisas em cidades turísticas. Anais do XII Encontro Nacional de Turismo com Base Local. Revista Brasileira de Ecoturismo, São Paulo, v.5, n.4, nov-2012, p.796.

\title{
Geografia urbana e as novas centralidades como subsídio as pesquisas em cidades turísticas
}

\author{
Wilson Martins Lopes Junior* \\ *Universidade Federal Fluminense \\ E-mail: prof.wilsonmartinslopes@uol.com.br
}

Diversas são as mudanças espaciais que ocorrem nas cidades de acordo com estrutura, processo, função e forma. Quando se trata de uma localidade turística essas questões urbanas merecem maior atenção devido a sua complexidade, também por conta da necessidade do turismo em utilizar os elementos deste espaço. Dentre as mudanças espaciais urbanas estão as referentes aos espaços públicos, à especulação imobiliária, às políticas públicas, às novas centralidades e à segregação socioespacial. No surgimento de novas centralidades urbanas, ocorre uma dinâmica contraditória de concentração e descentralização dos espaços urbanos que redefine as relações centro-periferia. Nesta perspectiva o tecido urbano é reorganizado e fragmentado junto às novas localizações das empresas de comércio e serviços, como as de turismo. O resultado é o surgimento de espaços internos de produção, moradia e de consumo que alteram o valor destas áreas criando centros com funções distintas que influem na segregação socioespacial. No contexto de turismo e urbanização, este ensaio, sustentando-se no conhecimento teórico da geografia urbana, se propôs a auxiliar as pesquisas de turismo urbano através da discussão a respeito das novas centralidades urbanas. As ideias e referências expostas constituem possibilidades de entendimentos para a questão do turismo como elemento urbanizador.

PALAVRAS-CHAVE: Turismo e Urbanização; Turismo e Espaço Urbano; Novas Centralidades; 